bloom dynamics depend principally on the impact of consumers, a long-recognized control of phytoplankton abundance (30). Our findings for Synechococcus agree with those of Behrenfeld and Boss in so far as division rates (and, by inference, loss rates) are roughly 10 times the accumulation (net growth) rates. Our results differ, however, in that we find a significant positive correlation between division and accumulation rates over the course of the spring bloom (Fig. 4, $\mathrm{B}$ and $\mathrm{C}$ ). This correlation was not detected by Behrenfeld and Boss, and perhaps should not be expected to be evident in the satellite-based observations of chlorophyll concentration that they analyzed (29). Those observations aggregate the entire phytoplankton community over a relatively large region of the ocean and mask individual responses of different taxa.

Our observations, made at a much smaller spatial scale and with much finer taxonomic and temporal resolution than that of satellite data, reveal a connection between division rates and the bloom dynamics of Synechococcus. Consumers (including grazers, viruses, and parasites) certainly play a major role in shaping the bloom's trajectory, but the bloom is triggered by an environmental factor, the seasonal temperature rise, which leads to increases in the Synechococcus division rate (Fig. 3). The bloom persists until the division rate plateaus (Fig. 4B), at which point losses overtake division and the bloom begins to decline.

We were able to diagnose the importance of temperature in regulating the dynamics of a ubiquitous marine primary producer, Synechococcus, by exploiting a 13-year time series comprising data on millions of individual cells and their traits. This allowed us to not only quantify the relationship between temperature and cell division in a natural population, but also to document how that relationship is the basis for a dramatic phenological shift affecting both Synechococcus and their consumers. It remains to be seen whether this ecological coupling will hold as warming trends continue in the decades to come.

\section{REFERENCES AND NOTES}

1. K. R. Arrigo, D. Worthen, A. Schnell, M. P. Lizotte, J. Geophys. Res. Oceans 103, 15587-15600 (1998).

2. P. Martin et al., Deep Sea Res. Part I Oceanogr. Res. Pap. $\mathbf{5 8}$ 338-349 (2011)

3. R. Ji, M. Edwards, D. L. Mackas, J. A. Runge, A. C. Thomas, J. Plankton Res. 32, 1355-1368 (2010)

4. K. H. Wiltshire et al., Estuaries Coasts 33, 295-310 (2010).

5. M. Kahru, V. Brotas, M. Manzano-Sarabia, B. G. Mitchell, Glob. Change Biol. 17, 1733-1739 (2011)

6. M. Edwards, A. J. Richardson, Nature 430, 881-884 (2004).

7. A. McQuatters-Gollop et al., Nature 472, E6-E7, discussion E8-E9 (2011)

8. W. W. Gregg, C. S. Rousseaux, J. Geophys. Res. Oceans 119 5921-5933 (2014)

9. D. G. Boyce, M. Dowd, M. R. Lewis, B. Worm, Prog. Oceanogr. 122. 163-173 (2014)

10. D. A. Siegel et al., Remote Sens. Environ. 135, 77-91 (2013).

11. R. J. Olson, A. A. Shalapyonok, H. M. Sosik, Deep Sea Res. Part I Oceanogr. Res. Pap. 50, 301-315 (2003)

12. J. B. Waterbury. S. W. Watson, F. W. Valois, D. G. Franks, Can. Bull. Fish. Aquat. Sci. 214, 71-120 (1986).

13. S. W. Nixon, S. Granger, B. A. Buckley, M. Lamont, B. Rowell, Estuaries 27, 397-404 (2004).
14. N. S. R. Agawin, C. M. Duarte, S. Agusti, Mar. Ecol. Prog. Ser 170, 45-53 (1998)

15. W. K. W. Li, Limnol. Oceanogr. 43, 1746-1753 (1998)

16. A.-Y. Tsai, K.-P. Chiang, J. Chang, G.-C. Gong, Aquat. Microb. Ecol. 51, 263-274 (2008)

17. K. R. Hunter-Cevera et al., Proc. Natl. Acad. Sci. U.S.A. 111 , 9852-9857 (2014)

18. W. K. W. Li, W. G. Harrison, E. J. H. Head, Proc. R. Soc. London Ser. B 273, 1953-1960 (2006).

19. L. R. Moore, R. Goericke, S. W. Chisholm, Mar. Ecol. Prog. Ser. 116. 259-275 (1995)

20. J. Pittera et al., ISME J. 8, 1221-1236 (2014).

21. M. R. Landry, R. P. Hassett, Mar. Biol. 67, 283-288 (1982).

22. R. E. McDuff, S. W. Chisholm, Limnol. Oceanogr. 27, 783-788 (1982).

23. M. Dugenne et al., Front. Microbiol. 5, 485 (2014).

24. F. Ribalet et al., Proc. Natl. Acad. Sci. U.S.A. 112, 8008-8012 (2015)

25. A. Calbet, M. R. Landry, Limnol. Oceanogr. 49, 51-57 (2004)

26. K. R. Hunter-Cevera, thesis, Massachusetts Institute of Technology and Woods Hole Oceanographic Institution (2014).

27. K. R. Hunter-Cevera, A. F. Post, E. E. Peacock, H. M. Sosik, Microb. Ecol. 71, 276-289 (2016)

28. A. Fischer et al., Oceanography 27, 222-235 (2014).

29. M. J. Behrenfeld, E. S. Boss, Annu. Rev. Mar. Sci. 6, 167-194 (2014).
30. K. Banse, in Primary Productivity and Biogeochemical Cycles in the Sea, P. G. Falkowski, A. D. Woodhead, K. Vivirito, Eds. (Springer, 1992), pp. 409-440.

\section{ACKNOWLEDGMENTS}

We thank E. T. Crockford, E. Peacock, J. Fredericks, the MVCO Operations Team, the captain and mate of the R/V Tioga, and P. Henderson of the Woods Hole Oceanographic Institution (WHOI) Nutrient Analytical Facility for logistical and analytical support. We thank S. W. Chisholm and J. Waterbury for discussions and comments on the manuscript. This work was supported by U.S. NSF grants OCE-0119915, OCE-0530830, OCE-1031256, DEB-1145017, and DEB-1257545; NASA grants NNX11AF07G and NNX13AC98G; Gordon and Betty Moore Foundation grant GGA\#934; the Investment in Science Fund, given primarily by WHOI Trustee and Corporation Members; and a National Defense Science and Engineering graduate fellowship from the U.S. Department of Defense. Data used in this study were deposited in the Dryad Digital Repository (http://dx.doi.org/10.5061/dryad.jm8s7)

\section{SUPPLEMENTARY MATERIALS}

www.sciencemag.org/content/354/6310/326/suppl/DC1 Materials and Methods

Figs. S1 to S8

References (31-33)

10 April 2016; accepted 9 September 2016

10.1126/science.aaf8536

\title{
Formaldehyde stabilization facilitates lignin monomer production during biomass depolymerization
}

\author{
Li Shuai, ${ }^{1}$ Masoud Talebi Amiri, ${ }^{1}$ Ydna M. Questell-Santiago, ${ }^{1}$ Florent Héroguel, ${ }^{1}$ \\ Yanding Li, ${ }^{2,3}$ Hoon Kim, ${ }^{2,4}$ Richard Meilan, ${ }^{5}$ Clint Chapple, ${ }^{6}$ \\ John Ralph, ${ }^{2,3,4}$ Jeremy S. Luterbacher ${ }^{1 *}$
}

Practical, high-yield lignin depolymerization methods could greatly increase biorefinery productivity and profitability. However, development of these methods is limited by the presence of interunit carbon-carbon bonds within native lignin, and further by formation of such linkages during lignin extraction. We report that adding formaldehyde during biomass pretreatment produces a soluble lignin fraction that can be converted to guaiacyl and syringyl monomers at near theoretical yields during subsequent hydrogenolysis (47 mole \% of Klason lignin for beech and 78 mole \% for a high-syringyl transgenic poplar). These yields were three to seven times those obtained without formaldehyde, which prevented lignin condensation by forming 1,3-dioxane structures with lignin side-chain hydroxyl groups. By depolymerizing cellulose, hemicelluloses, and lignin separately, monomer yields were between 76 and 90 mole \% for these three major biomass fractions.

L ignin is an abundant natural polymer, accounting for 15 to 30 weight \% (wt \%) of lignocellulosic biomass $(1,2)$. Unlike cellulose and hemicellulosic polysaccharides, the other major constituents of biomass, lignin primarily consists of methoxylated phenylpropanoid (guaiacyl and syringyl) subunits. This structure gives lignin an energy density $30 \%$ greater than that of polysaccharide polymers and makes it one of the few natural large-scale sources of aromatic compounds $(3,4)$. These properties make lignin-derived monomers useful precursors for renewable aromatic chemicals and drop-in fuels $(3,4)$.
The longstanding interest in lignin valorization has translated into few commercial processes because of the lack of practical high-yield lignin depolymerization methods that can be used while upgrading biomass polysaccharides. Promising biorefinery fractionation or pretreatment processes-such as those using water (5), alcohol (6), tetrahydrofuran (THF) (7), ionic liquids (IL) (8), and $\gamma$-valerolactone (GVL) $(9,10)$-use high temperatures and/or inexpensive mineral acids (such as $\mathrm{H}_{2} \mathrm{SO}_{4}$ and $\mathrm{HCl}$ ) that facilitate the removal of lignin and hemicelluloses $(5,11)$. A largescale source of lignin could likely come from a process using these technologies (4). However, the 
use of acid and/or high temperatures during lignin extraction leads to severe and irreversible condensation that dramatically affects its upgrading. Specifically, under the extraction conditions, lignin ether bonds are cleaved, and stable carbon-carbon $(\mathrm{C}-\mathrm{C})$ bonds are formed. The proposed mechanism involves the formation of highly reactive lignin side-chain (benzylic) carbocations that attack electron-rich lignin aromatic rings (Fig. 1A) (12, 13).

The most prevalent lignin depolymerization strategy is the direct hydrogenolysis of native lignin in biomass. Such processes usually involve mixing a heterogeneous metal catalyst with solid untreated biomass in a batch reactor, cleaving ether bonds in near theoretical yields to produce $\sim 45$ to 55 mole \% (mol \%) of monomers, along with enzyme-digestible pulps (14-17). Issues such as catalyst recovery and mass transfer limitations have nevertheless restricted the large-scale implementation of this method. The hydrogenolysis of extracted lignin could avoid these drawbacks and be implemented in a continuous process. However, the use of extracted lignin has led to monomer yields of typically 5 to $20 \mathrm{~mol} \%$, which is 3 to 10 times lower than those obtained from direct hydrogenolysis of native lignin due to the lignin degradation and condensation experienced during extraction (Fig. 1A) $(18,19)$. Oxidation of benzylic hydroxyl groups on cellulolytic enzyme lignin (CEL) (extracted from biomass by means of ball-milling and repeated enzymatic steps), followed by formic acid-catalyzed $\beta$-aryl ether cleavage, resulted in near theoretical yields of lignin monomers (50 mol \%, $\approx 61$ wt \% because of added oxygen) (20). However, largescale quantities of uncondensed CEL lignin are currently impossible to produce industrially. The use of GVL as a solvent for extracting lignin from corn (Zea mays) stover was shown to partially conserve lignin's $\beta$-ether bonds owing to its ability to solubilize lignin under mild conditions (21). Even this method led to yields below $70 \%$ of theoretical for corn stover and below $40 \%$ for maple (Acer spp.) wood, presumably because of lignin condensation reactions that occurred during its extraction (21).

Extracting a soluble and uncondensed lignin substrate during biomass pretreatment could facilitate the production of lignin monomers and be compatible with current biorefining strategies. The major challenge in developing such a process is to prevent interunit $\mathrm{C}-\mathrm{C}$ coupling during extraction (Fig. 1A). Our strategy was to attempt to block the reactive benzylic positions

${ }^{1}$ Laboratory of Sustainable and Catalytic Processing, Institute of Chemical Sciences and Engineering, École Polytechnique Fédérale de Lausanne (EPFL), CH-1015 Lausanne, Switzerland. ${ }^{2}$ U.S. Department of Energy (DOE) Great Lakes Bioenergy Research Center, Wisconsin Energy Institute, University of Wisconsin, Madison, WI 53726, USA.

${ }^{3}$ Department of Biological Systems Engineering, University of Wisconsin, Madison, WI 53706, USA. ${ }^{4}$ Department of Biochemistry, University of Wisconsin, Madison, WI 53706, USA. ${ }^{5}$ Department of Forestry and Natural Resources, Purdue University, West Lafayette, IN 47907. USA.

${ }^{6}$ Department of Biochemistry, Purdue University, West Lafayette, IN 47907, USA.

*Corresponding author. Email: jeremy.luterbacher@epfl.ch with a protecting agent during pretreatment. to stabilize lignin during extraction leads to near theoretical yields of lignin monomers after hydrogenolysis of the extracted product. These yields were three to seven times higher than those obtained when using the analogous method without FA (Fig. 1). Evidence suggests that FA actually hinders the formation of $\mathrm{C}-\mathrm{C}$ linkages through two mechanisms. First, in an acidic, water-deficient environment, FA reacts to form a stable six-membered 1,3-dioxane (acetal) structure with the 1,3-diols (and their $\alpha$ - and $\gamma$-hydroxyl groups) on lignin side-chains (Fig. 1B), blocking the formation of benzylic cations. Second, the electron-rich positions at the positions ortho or para to methoxyl groups on the aromatic ring are the most reactive for electrophilic aromatic substitution by (protonated) FA to form hydroxymethyl groups, blocking these reactive positions.

For initial tests, we used a model lignin dimer (veratrylglycerol- $\beta$-guaiacyl ether, VG, 1) (Fig. 2A), representing the predominant phenol-etherified $\beta$-O-4-linked ( $\beta$-aryl ether) units with their characteristic and available $\alpha$ - and $\gamma$-hydroxyl groups (22). Without FA, $\mathbf{1}$ depolymerized to form $\mathbf{3}$ and $\mathbf{4}$ through $\mathbf{2}$, as was consistent with a prior report (Fig. 2, A and C) (12). The low yield of $\mathbf{3}$ (40\%) compared with $\mathbf{4}(95 \%)$ after 7 hours was likely due to condensation reactions similar to those observed with real lignin. In the presence of FA, $\mathbf{1}$ was rapidly converted to $\mathbf{5}$ and $\mathbf{6}$ (Fig. 2, $\mathrm{B}$ and D). Comparison of two-dimensional heteronuclear single-quantum coherence nuclear magnetic resonance (2D HSQC NMR) spectra of pure $\mathbf{1}$ and the derived products obtained in the presence of FA (Fig. 2, E and F) revealed the formation of the 1,3-dioxane structures [FAderived $\mathrm{C} / \mathrm{H}$ pairs in Fig. 2 are colored in red; two pairs of peaks are seen for all of the product's $\mathrm{C} / \mathrm{H}$ correlations for the two (syn and anti, or threo and erythro) isomers], with chemical shift data We report here that using formaldehyde (FA)

matching those previously reported for $\mathbf{1}$ and the free-phenolic analogs of the acetals 5 (23).

After the acid treatment of $\mathbf{1}$, as in a typical biomass fractionation process, a hydrogenolysis step was performed to produce monomers (22). Using the products from the reaction without FA, 3 was quantitatively converted to veratrylpropyl compounds 7 (Fig. 2A and fig. S1, B, C, and D), with the low overall yields (43\%) confirming the loss of over half of the product $\mathbf{3}$ to condensation products before hydrogenolysis. In contrast, hydrogenolysis of the product mixture obtained in the presence of FA produced veratrylpropyl compounds $\mathbf{8}$ in $85 \%$ yield along with $87 \%$ for guaiacyl compounds $\mathbf{9}$ (Fig. $2 \mathrm{~B}$ and fig. S1). This substantial increase in yield with FA addition ( 85 versus $43 \%$ ) reflects the stabilizing effect that FA has on real lignin (Fig. 1).

We observed the hydroxymethylation of aromatic rings with FA via the additional ring methylation in several VG $\mathbf{1}$ reaction products (8 and 9) and when reacting several lignin monomers with FA followed by hydrogenolysis (fig. S2). Hydroxymethylation appears to act as a secondary lignin stabilization mechanism, as demonstrated with condensation studies using vanillyl alcohol, which can polymerize like lignin but cannot form a dioxane structure with FA (22).

We used beech (Fagus grandifolia) wood (particle size, $<0.45 \mathrm{~mm}$; moisture content, $5.7 \%$ ) to test the effect of FA during the extraction of real lignin using similar reaction conditions (22). HSQC spectra from lignin extracted in the presence of FA (Fig. 3A, right) revealed the presence of the 1,3-dioxane structures analogous to those observed with model compounds (Fig. 2F). Without FA addition, no dioxane structure signals were observed, and signals characteristic of the native lignin side-chains were also absent (Fig. 3A, left). This disappearance was consistent with the results of previous studies of lignin condensation $(24,25)$. In addition, the color of

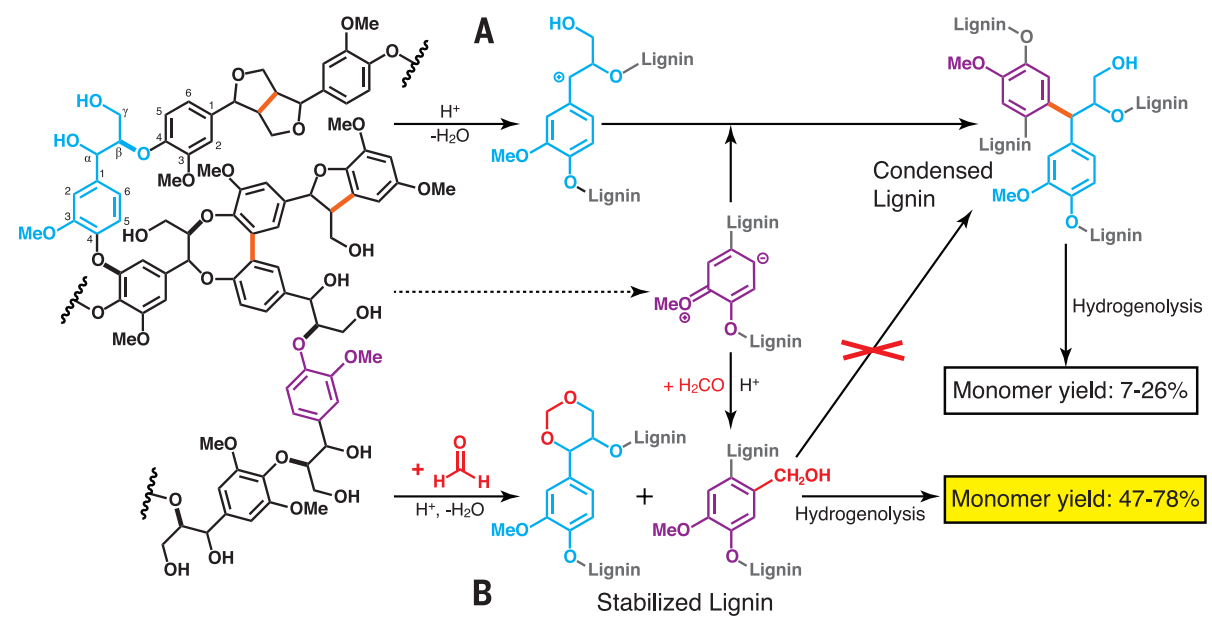

Fig. 1. Lignin monomer production by extraction followed by hydrogenolysis. (A) Lignin extraction, condensation, and hydrogenolysis in a standard acidic process. (B) Lignin extraction, stabilization with FA, and hydrogenolysis. Monomer yields, on a molar basis, are based on native Klason lignin. Bold bonds are those formed during the radical coupling reactions of lignification. The bonds highlighted in orange represent interunit $\mathrm{C}-\mathrm{C}$ linkages. 
the lignin obtained in the presence of FA was substantially lighter than that obtained in its absence, serving as a qualitative indicator of reduced condensation (fig. S3). We also tested the effect of FA in a similar manner using an extremely high-S poplar, to be described below. In this case, all of the features of the 1,3-dioxanederivatized and purified lignin, along with some hydroxymethylation of the ring, could be readily discerned and assigned with the aid of model compounds run under the same conditions (Fig. 3B).
Lignin monomer identification and quantification are described extensively in the supplementary materials (22). Five major lignin monomers were identified in the products without FA addition, or from the direct hydrogenolysis of native lignin (Fig. 3, C and D, and fig. S4), that were all consistent with previous reports (16). With FA addition, five additional methylated monomers were identified (Fig. 3, $\mathrm{C}$ and D, and figs. S4 and S5) (22). The addition of FA did not substantially affect lignin removal, but final monomer yields after hydrogenolysis of the extracted lignin were remarkably elevated (Fig. 3B). Without FA addition, hydrogenolysis of the extracted lignin resulted in a monomer yield of $7 \%$, which is consistent with previous studies (26). With FA addition, the highest yield was $47 \%$ after hydrogenolysis of the extraction liquor (Fig. 3B). We attribute the increased monomer yield obtained with FA primarily to the same stabilization mechanism observed with the model lignin dimer (Figs. 1 and 2). This yield (47\%) was comparable with the yield of $48 \%$ obtained through direct hydrogenolysis of the
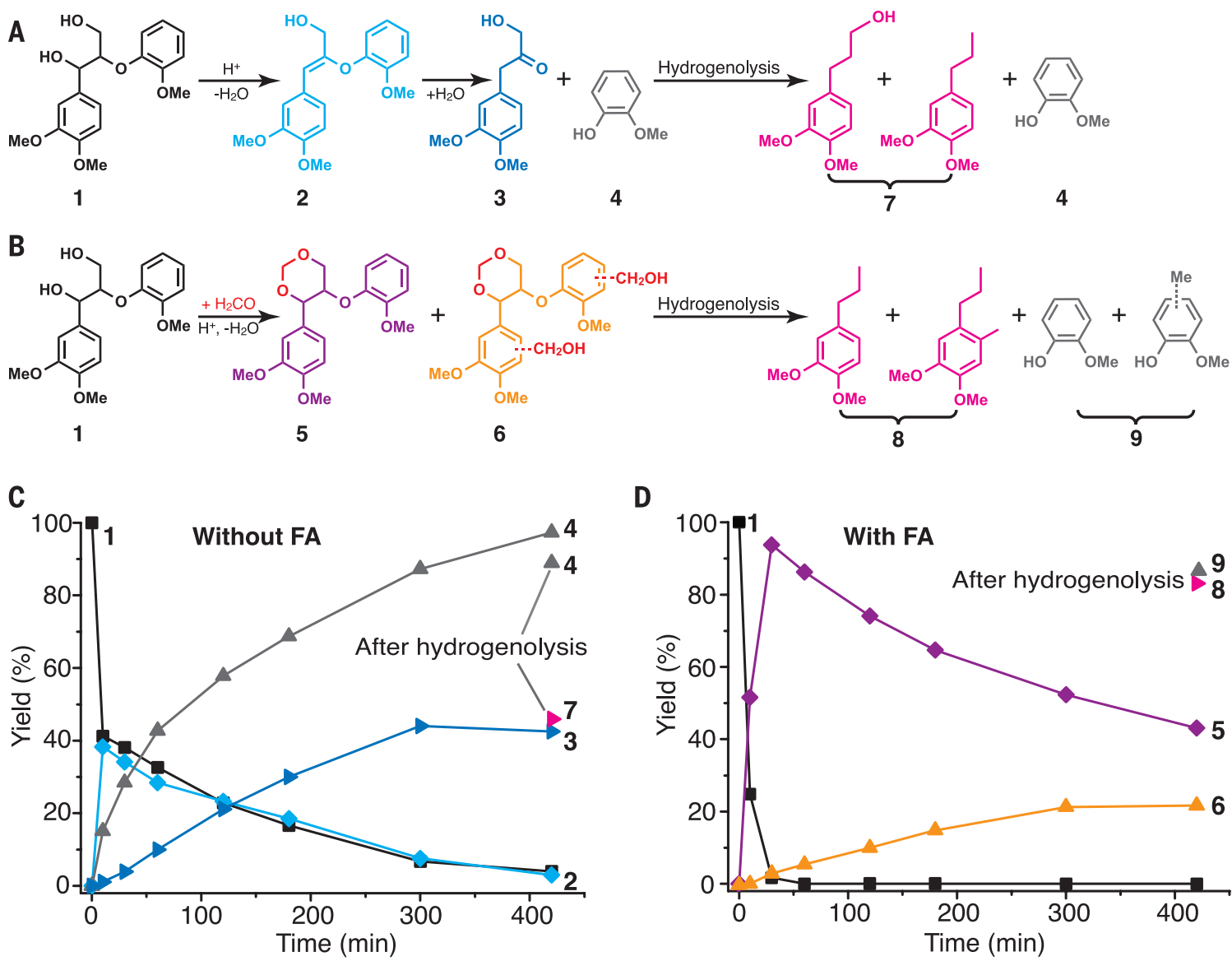

D

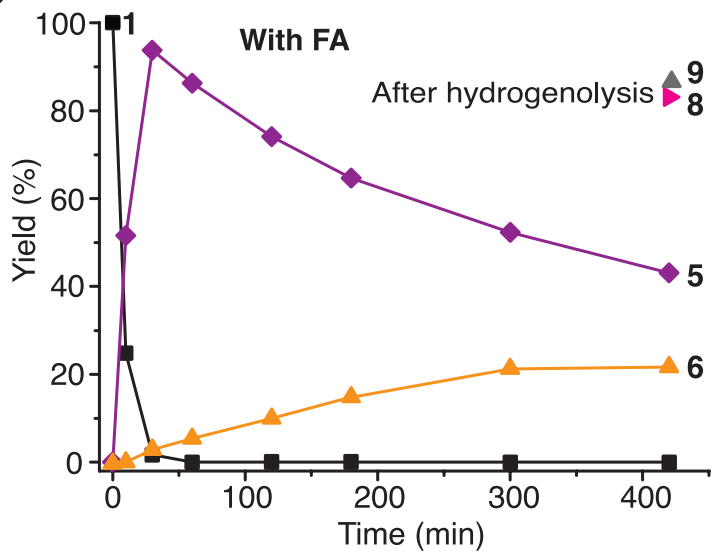

$\mathbf{E}$

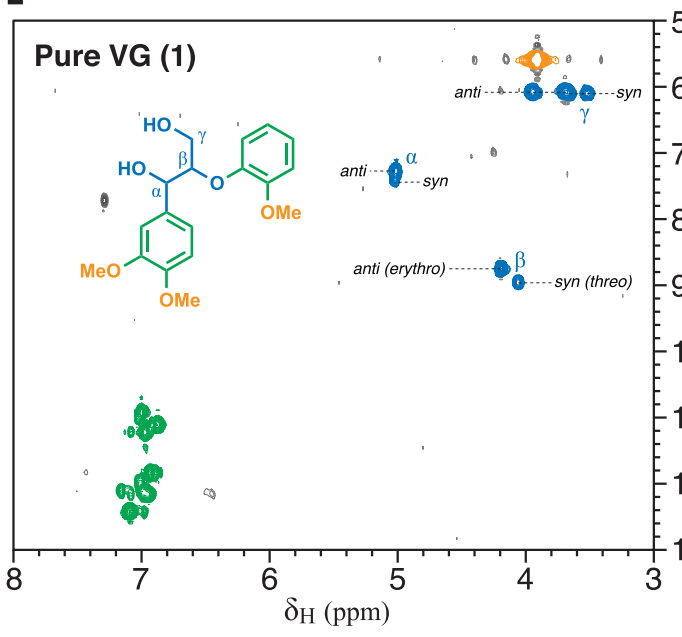

$\mathbf{F}$
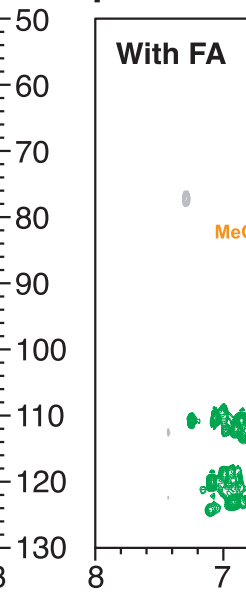

Fig. 2. Acid-catalyzed depolymerization of veratrylglycerol$\beta$-guaiacyl ether 1.

(A) Without FA. (B) With FA. (C) Time course of reaction (A). (D) Time course of reaction (B). (E) 2D HSQC NMR spectrum of pure VG 1. (F) 2D HSQC NMR spectrum of the product mixture resulting from reaction (B) after $30 \mathrm{~min} . \delta_{\mathrm{H}}$, proton NMR chemical shift (in parts per million); $\Delta \mathrm{C}$, carbon NMR chemical shift (in parts per million). 

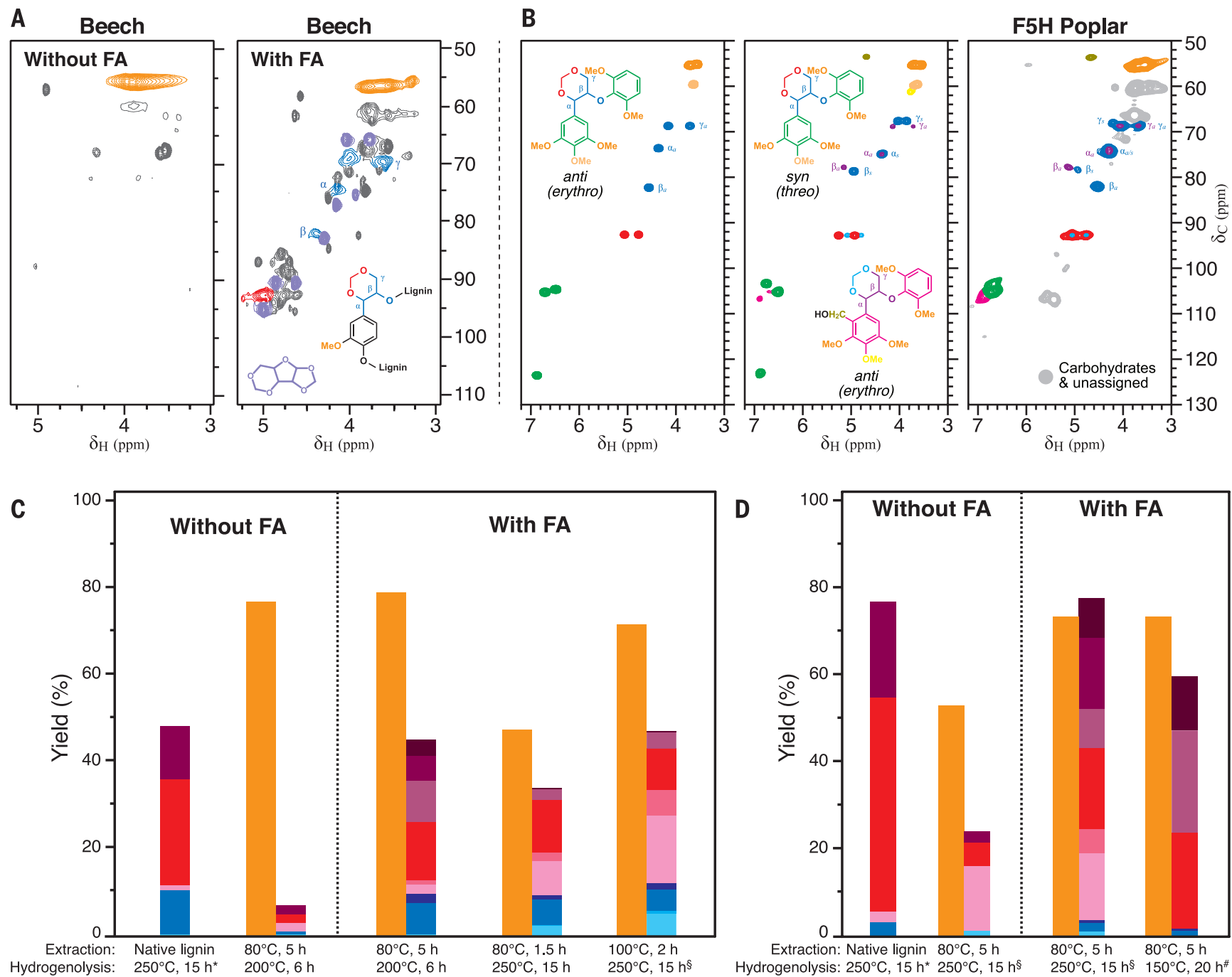

\section{Monomer yield:}

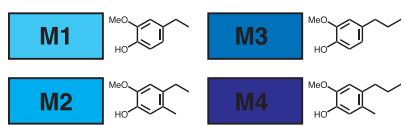

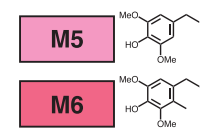

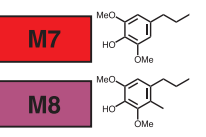

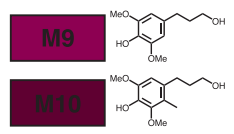

Extracted lignin yield:

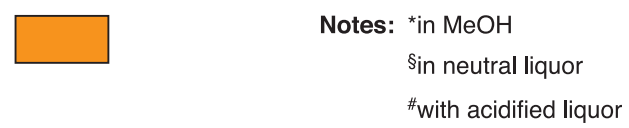

Fig. 3. Production of lignin monomers from lignocellulosic biomass. (A) $2 D$ HSQC NMR spectra of lignin extracted from beech wood in the absence and presence of FA. Signals attributed to diformyl-xylose (fig. S6) are highlighted in light purple. (B) The same extraction by using high-syringyl F5H-poplar (after a precipitative purification of the lignin, right), and assignments from authentic syringyl model compounds for the produced dioxanes. (C) Lignin monomer yields from beech wood (table S1, entries 1 to 5). (D) Lignin monomer yields from high-syringyl F5H-poplar (table S1, entries 14, 15, 16, and 22).

wood $(14,16)$ and with the yields obtained by using established lignin monomer analysis methods, including derivatization followed by reductive cleavage (DFRC) (27) and nitrobenzene oxidation (NBO) (fig. S7) (28).

We applied this method to softwood (spruce, Picea abies) (particle size, $<1.5 \mathrm{~mm}$; moisture content, $6.6 \%$ ) and obtained a yield of $21 \%$-the same yield obtained with direct hydrogenolysis (table S1). These relatively low monomer yields are consistent with previous reports using softwoods $(15,16)$ and likely are due in part to the higher native levels of interunit $\mathrm{C}-\mathrm{C}$ linkages in softwoods as compared with hardwoods.
Our strategy for improving lignin monomer yields is to hinder the formation of $\mathrm{C}-\mathrm{C}$ linkages during lignin extraction. Thwarting the production of such linkages by altering the native lignin could further increase yields $(3,29)$. Overexpression of the ferulate 5-hydroxylase gene in poplar (Populus spp., F5H-poplar) (particle size, $<1 \mathrm{~mm}$; moisture content, $6.7 \%$ ) yields lignin that has a high content of syringyl units (98.3\%) and reduced native interunit $\mathrm{C}-\mathrm{C}$ linkages $(88.8 \% \beta-\mathrm{O}-4$ linkages, $4.2 \% \beta-1$ linkages, and $7.1 \% \beta-\beta$ linkages) (fig. S8). Because of the high-S nature of this lignin, there was a simpler array of major products, and using FA stabilization, we obtained lignin monomer yields of up to $78 \%$ after hydrogenolysis of the extracted substrate (Fig. 3D). This yield was comparable with that obtained through direct hydrogenolysis of F5H-poplar (77\%). In contrast, a monomer yield of only $24.5 \%$ was obtained from its native wood lignin without FA addition. Furthermore, monomer selectivities from the isolated soluble F5H-poplar lignin were quantitative, which was confirmed with gel permeation chromatography of the lignin before and after hydrogenolysis. After hydrogenolysis, the broad lignin oligomer peak (molecular weight $\approx$ $2900 \mathrm{~g} / \mathrm{mol}$ ) had disappeared, and essentially only a single monomer peak remained (fig. S9). 
A

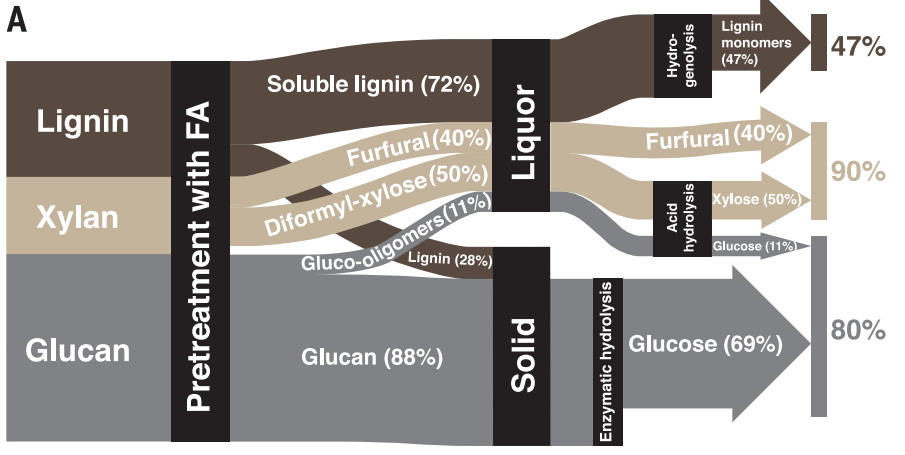

B

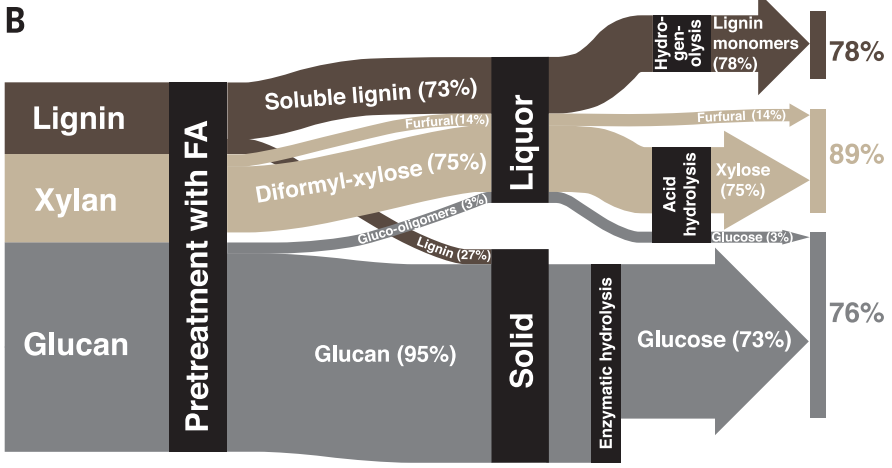

Fig. 4. Mass balance of polysaccharide (glucan and xylan) and lignin fractions of biomass. (A) Beech wood (table S1, entry 3). (B) F5H-poplar wood (table S1, entry 16). The corresponding reaction conditions are summarized in table S3.

These advantages illustrate the potential benefits of optimizing lignin biosynthesis for improved lignin valorization.

Selectively hydrogenating only the extracted upgradeable lignin, as opposed to recalcitrant lignin and other biomass derivatives, could facilitate continuous processing and increase the selective use of $\mathrm{H}_{2}$ by avoiding the hydrogenation of recalcitrant lignin or other biomass fractions. FA-extracted lignin can also be converted to monomers at $150^{\circ} \mathrm{C}$ (instead of $250^{\circ} \mathrm{C}$ ) if acid is present to break the 1,3-dioxane ring structure (Fig. 3C); direct hydrogenolysis of F5Hpoplar at $150^{\circ} \mathrm{C}$ under neutral conditions leads to negligible monomer production. Under acidic conditions, direct hydrogenolysis leads to lower yields (48 versus $60 \%$ ) than with FA extraction (table S1) and to substantial loss of the polysaccharide fraction of biomass (table S2). The comparison demonstrates the advantages of using FA-extracted lignin to generate monomers separately from the polysaccharides at low hydrogenolysis temperatures.

In contrast to direct biomass hydrogenolysis, extracting a soluble stabilized lignin fraction before its hydrogenolysis is compatible with most polysaccharide depolymerization approaches. With FA present, $40 \%$ of xylan was dehydrated into furfural, and $50 \%$ reacted with FA to form diformyl-xylose (structure given in Fig. 3A and fig. S6), which could be converted back to xylose under aqueous acidic conditions (Fig. 4 and supplementary materials, section S2.3) (22). High yields of glucose $(80 \%)$ were obtained after enzymatic hydrolysis of the leftover solids, which required further treatment in an aqueous dilute acid solution ( $1 \mathrm{wt} \% \mathrm{H}_{2} \mathrm{SO}_{4}$ ) to remove grafted FA on the surface of substrates (supplementary materials, section S2.3) (22). Therefore, the treatment of beech wood under acidic conditions in the presence of FA leads to overall yields of $47 \%$ lignin monomers (theoretical yield for its $\beta$-ether content), $80 \%$ glucose, $40 \%$ furfural, and $50 \%$ xylose (90\% overall yield from xylan) (Fig. $4 \mathrm{~A}$ ). With F5H-poplar, yields of $78 \%$ lignin monomers, $76 \%$ glucose, $14 \%$ furfural, and $75 \%$ xylose $(89 \%$ overall yield from xylan) were obtained.
These results suggest that lignin upgrading could be easily integrated into current biorefinery schemes, especially considering that FA is a relatively inexpensive bulk chemical that can be produced from biomass-derived syngas or methanol, either sourced biologically or from lignin methoxyl groups (14). Furthermore, we estimated that FA consumed for stabilizing lignin represented $\sim 1.9$ wt \% of the original biomass, with the remaining FA being recoverable (supplementary materials, section S2.4) (22). Studies with ${ }^{13} \mathrm{C}$-labeled FA demonstrated that FA consumed by lignin ended up either as methyl groups on the lignin aromatic rings or as methane after hydrogenolysis (supplementary materials, section S2.4) (22). Although processes exist for converting methane back to FA, we estimated that the cost of replacing FA would be $9 \%$ of the cost of monomers (supplementary materials, section S2.4) (22).

\section{REFERENCES AND NOTES}

1. J. Zakzeski, P. C. A. Bruijnincx, A. L. Jongerius,

B. M. Weckhuysen, Chem. Rev. 110, 3552-3599 (2010).

2. J. Ralph et al., Phytochem. Rev. 3, 29-60 (2004).

3. R. Rinaldi et al., Angew. Chem. Int. Ed. Engl. 55, 8164-8215 (2016)

4. A. J. Ragauskas et al., Science 344, 1246843 (2014).

5. J. S. Luterbacher, D. M. Alonso, J. A. Dumesic, Green Chem. 16 4816-4838 (2014)

6. X. Pan et al., Biotechnol. Bioeng. 90, 473-481 (2005).

7. T. Y. Nguyen, C. M. Cai, R. Kumar, C. E. Wyman, ChemSusChem 8, 1716-1725 (2015).

8. H. Tadesse, R. Luque, Energy Environ. Sci. 4, 3913-3929 (2011)

9. L. Shuai, Y. M. Questell-Santiago, J. S. Luterbacher Green Chem. 18, 937-943 (2016)

10. J. S. Luterbacher et al., Science 343, 277-280 (2014).

11. L. Shuai, J. Luterbacher, ChemSusChem 9, 133-155 (2016)

12. M. R. Sturgeon et al., ACS Sustain. Chem. Eng. 2, 472-485 (2014).

13. K. Shimada, S. Hosoya, T. Ikeda, J. Wood Chem. Technol. 17 , 57-72 (1997).

14. N. Yan et al., ChemSusChem 1, 626-629 (2008).

15. T. Parsell et al., Green Chem. 17, 1492-1499 (2015).

16. S. Van den Bosch et al., Energy Environ. Sci. 8, 1748-1763 (2015).

17. J. M. Pepper, Y. W. Lee, Can. J. Chem. 47, 723-727 (1969).
18. V. M. Roberts et al., Chemistry 17, 5939-5948 (2011)

19. C. Xu, R. A. D. Arancon, J. Labidi, R. Luque, Chem. Soc. Rev. 43, 7485-7500 (2014)

20. A. Rahimi, A. Ulbrich, J. J. Coon, S. S. Stahl, Nature 515 , 249-252 (2014)

21. J. S. Luterbacher et al., Energy Environ. Sci. 8, 2657-2663 (2015).

22. Materials and methods are available as supplementary materials on Science Online.

23. S. Ralph, J. Ralph, L. Landucci, NMR database of lignin and cell wall model compounds (2009); www.glbrc.org/databases and_software/nmrdatabase.

24. L. Shuai et al., Bioresour. Technol. 101, 3106-3114 (2010)

25. H. L. Trajano et al., Biotechnol. Biofuels 6, 110 (2013).

26. H. Wang, M. Tucker, Y. Ji, J. Appl. Chem. 2013, 1-9 (2013)

27. S. D. Karlen et al., Sci. Adv. 10.1126/sciadv.1600393 (2016)

28. Y. Li, T. Akiyama, T. Yokoyama, Y. Matsumoto, Biomacromolecules 17, 1921-1929 (2016)

29. J. J. Stewart, T. Akiyama, C. Chapple, J. Ralph, S. D. Mansfield, Plant Physiol. 150, 621-635 (2009).

\section{ACKNOWLEDGMENTS}

This work was supported by the Swiss Competence Center for Energy Research: Biomass for a Swiss Energy Future through the Swiss Commission for Technology and Innovation grant KTI.2014.0116; by the Swiss National Science Foundation through grant PYAPP2_154281; and by EPFL. J.R., Y.L., and H.K. were funded by the DOE Great Lakes Bioenergy Research Center (DOE BER Office of Science DE-FC02-07ER64494). R.M. and C.C. were funded by the Center for Direct Catalytic Conversion of Biomass to Biofuels (C3Bio), an Energy Frontier Research Center funded by the DOE Office of Science, Office of Basic Energy Sciences, award DE-SC0000997. We thank M. Studer for providing us with beech and spruce wood. All data are provided in the supplementary materials. J.S.L. and L.S. are inventors on European patent application EP 16165180.7 submitted by EPFL, which covers methods for producing lignin monomers from biomass during biomass depolymerisation. C.C. is an inventor on U.S. patent 6610908 held by the Purdue Research Foundation, which covers manipulation of lignin composition in plants by using a tissue-specific promoter.

\section{SUPPLEMENTARY MATERIALS}

www.sciencemag.org/content/354/6310/329/suppl/DC1 Materials and Methods

Supplementary Text

Figs. S1 to S22

Tables S1 to S11

References (30-45)

8 May 2016; accepted 14 September 2016 10.1126/science.aaf7810 


\section{$\begin{array}{r}\text { Science } \\ \text { MIAAS } \\ \hline\end{array}$}

Editor's Summary

\section{Formaldehyde stabilization facilitates lignin monomer production during biomass depolymerization}

Li Shuai, Masoud Talebi Amiri, Ydna M. Questell-Santiago, Florent Héroguel, Yanding Li, Hoon Kim, Richard Meilan, Clint Chapple, John Ralph and Jeremy S. Luterbacher (October 20, 2016)

Science 354 (6310), 329-333. [doi: 10.1126/science.aaf7810]

\section{Formaldehyde protects and serves}

The lignin found in plants is a desirable renewable feedstock for fuels and other useful compounds. Breaking down such a strong, energy-dense polymer, however, requires pretreatment of plant biomass under harsh conditions. These pretreatment steps often cause side reactions within the polymer itself, which lower the overall yields of lignin monomers. Shuai et al. used formaldehyde during pretreatment to block the reactive groups that lead to carbon-carbon linkages in lignin. This simple step stabilized lignin during pretreatment, resulting in dramatically improved yields.

Science, this issue p. 329

This copy is for your personal, non-commercial use only.

Article Tools Visit the online version of this article to access the personalization and article tools:

http://science.sciencemag.org/content/354/6310/329

Permissions Obtain information about reproducing this article:

http://www.sciencemag.org/about/permissions.dtl

Science (print ISSN 0036-8075; online ISSN 1095-9203) is published weekly, except the last week in December, by the American Association for the Advancement of Science, 1200 New York Avenue NW, Washington, DC 20005. Copyright 2016 by the American Association for the Advancement of Science; all rights reserved. The title Science is a registered trademark of AAAS. 